\title{
Experiences with Sandvik grades in oil refinery applications
}

\author{
Jonas Höwing ${ }^{1, *}$, Angela Philipp ${ }^{2}$ \\ ${ }^{1}$ Sandvik Materials Technology, 43135 Mölndal, Sweden \\ ${ }^{2}$ Sandvik Materials Technology Deutschland GmbH, 40549 Düsseldorf, Germany
}

\begin{abstract}
A modern refinery can have more than a thousand of heat exchangers, of which the clear majority comprises tubes made of carbon or low alloyed steel. In some special applications severe conditions can occur where the use of low alloyed steels does not give enough life time and in the worst cases causes unplanned shutdowns. Among the most problematic heat exchangers in a refinery are the overhead condensers in atmospheric and vacuum distillation units, but also others within the refineries can have highly corrosive conditions. The most common problems are condensation of hydrochloric acid, diluted chlorides in acidic water phases, deposits and formation of chloride salts such as ammonium chloride. These conditions can induce general and under deposit corrosion, pitting and stress corrosion cracking. Other units in the refineries where high alloyed stainless steel or nickel base alloys are commonly encountered are in hydrotreaters and reactor effluent air coolers (REACs). In this paper experiences from installations of high alloyed stainless steels tubes in critical refinery heat exchangers will be discussed. Comparisons of different grades, their performances and limitations depending on the environments, will also be addressed.
\end{abstract}

\section{High Alloyed Materials}

\subsection{Duplex and Austenitic Stainless-Steel Grades}

Duplex stainless steels with a dual ferrite-austenite microstructure are characterised by a very high yield strength, good resistance to localised corrosion such as pitting and crevice corrosion and excellent resistance towards chloride induced stress corrosion cracking $(\mathrm{Cl}-$ $\mathrm{SCC}$ ). Table 1 shows a comparison of $\mathrm{Cr}, \mathrm{Mo}, \mathrm{N}$ and $\mathrm{Ni}$ contents of some duplex and austenitic grades and their respective pitting resistance equivalent (PRE). It can be seen, that if it comes to pitting corrosion resistance there are duplex alternatives for the common austenitic alloys. Since the duplex grades contains low amounts of nickel, they are usually cheaper options on a weight per weight basis then their austenitic counterparts.

Table 1. Comparison chemical composition of some austenitic and grades and their duplex counterparts. clarification. PRE is a theoretical value comparing the resistance toward pitting corrosion of different stainless steel grades in a chloride containing environment.

\begin{tabular}{|c|c|c|c|c|c|}
\hline UNS & Cr & Mo & N & Ni & PRE* \\
\hline S31603 & 17 & 2.6 & - & 17 & 26 \\
\hline S32304 & 23 & 0.3 & 0.1 & 4 & 26 \\
\hline N08904 & 20 & 4.5 & - & 25 & 33 \\
\hline S32205 & 22 & 3.2 & 0.18 & 5 & 35 \\
\hline S31254 & 18 & 6.1 & 0.2 & 20 & 43 \\
\hline S32750 & 25 & 4 & 0.3 & 7 & 42 \\
\hline S32707 & 27 & 4.8 & 0.4 & 7 & 49 \\
\hline
\end{tabular}

\footnotetext{
* Corresponding author: jonas.howing $@$ sandvik.com;
}

Compared to austenitic grades the higher yield strength of duplex steels allows to work with reduced wall thicknesses, which provides an increased heat transfer and support a higher total flow of process media on the tube side. A concern that is often raised to duplex steels is that they are difficult to fabricate. Especially welding is a concern with many fabricators. What is often not recognised though is that some aspects of duplex steel in fabrication is easier than with austenitic grades. Duplex grades are still advanced materials and welding even low alloyed S32304 duplex is not forgiving as welding S30403 or S31603. Especially the nitrogen content of the duplex grades needs to be preserved, usually achieved by having nitrogen in the shielding and backing gases. Significant loss of nitrogen from the duplex stainless steel will have negative impact on the corrosion resistance of the material.

One advantage when using duplex grades are that cold formed material, e.g. U-bent tubes, in general do not need to be stress relieved (heat treated). The reason that the duplex grades not needing stress relieving after being cold worked is their natural excellent resistance towards stress corrosion cracking in chloride containing environments. 


\section{Corrosion Mechanism in refinery applications}

\subsection{Pitting and crevice corrosion}

Resistance of stainless steel to pitting corrosion is mainly governed by the alloy's concentration of chromium, molybdenum, tungsten and nitrogen.

In Fig. 1 and Fig.1.1 critical pitting and crevice corrosion temperature (CPT and CCT, respectively) from ASTM G48 testing is shown [1]. The test method is a very severe with high chloride content, high corrosion potential and low $\mathrm{pH}$ and is usually quite different from actual process conditions. Nevertheless, results from this test method can be used as a guide when selecting alloys for chloride containing environment.

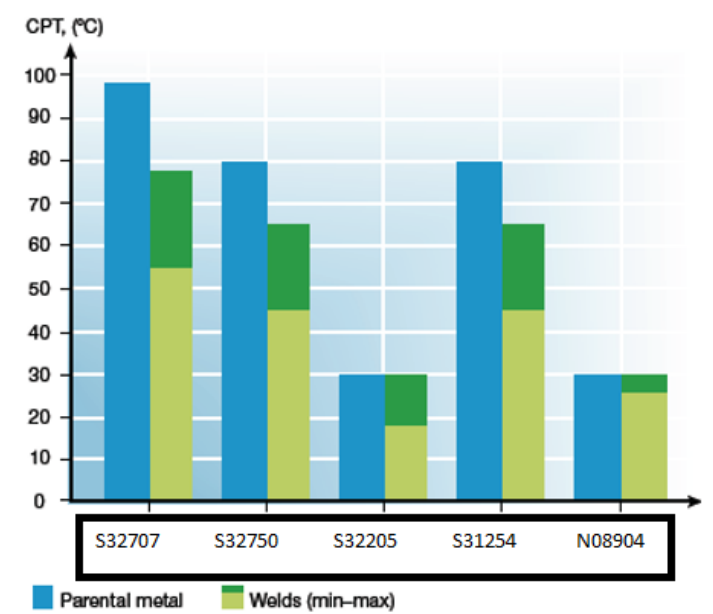

Fig. 1. CPT $=$ Critical Pitting Temperature for S3270, S32750, $\mathrm{S} 32205, \mathrm{~S} 31254$ and $\mathrm{N} 08904$ in $6 \% \mathrm{FeCl}_{3}$ determined in the ASTM G48A test where the samples are exposed to $6 \% \mathrm{FeCl}_{3}$ solution for $24 \mathrm{~h}$ and the temperature when pitting starts to develop is determined.

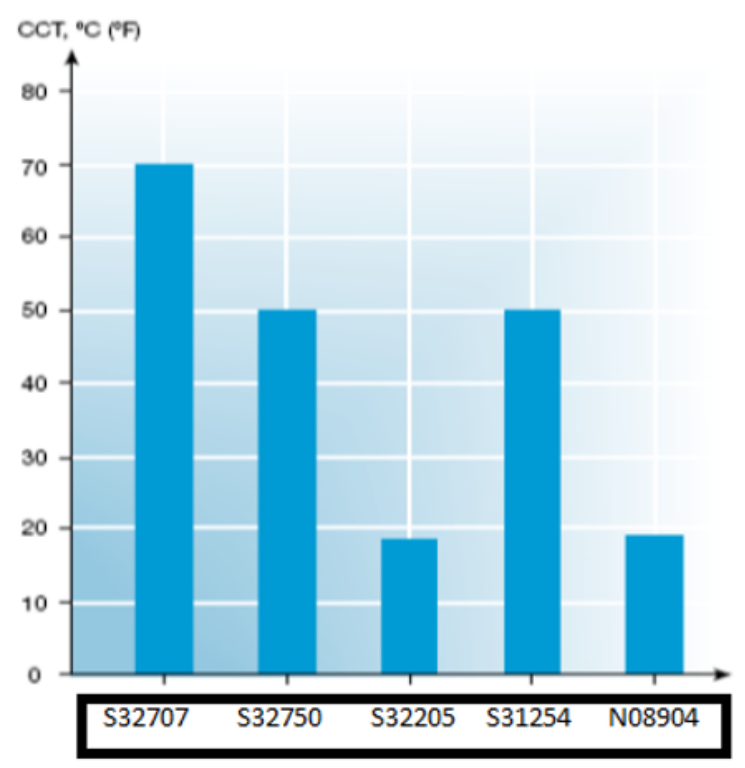

Fig. 1.1 Approximate values for the critical crevice corrosion temperature (CCT) after exposure in $6 \% \mathrm{FeCl}_{3}$ for $24 \mathrm{~h}$ according to ASTM TP G48B. In practice the values may differ somewhat from these owing to variations in crevice gap and surface condition.

\subsubsection{Seawater corrosion}

Seawater is sometimes used as media to cool process streams. Seawater is a very special environment as it not only contains a lot of chlorides, but also other dissolved salts that can give rise to solid deposits. In addition, algae, bacteria, seaweed and molluscs can give rise to biofilms and following microbiological induced corrosion, under deposit corrosion and clogging of the seawater system. To mitigate the microbiological growth in the system, chlorination is commonly used. Unfortunately, this lead to increased corrosion potential and a more corrosive system (Fig. 2).

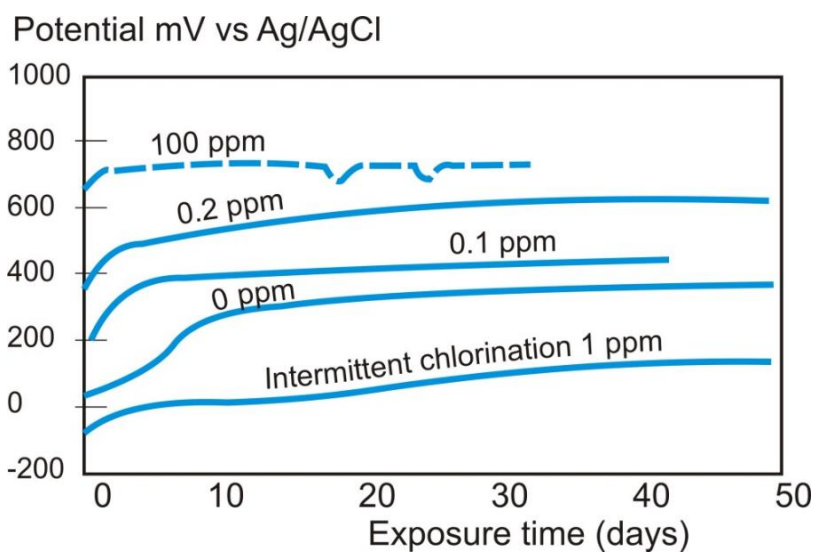

Fig. 2. Corrosion potential of stainless steels as a function of chlorination method in natural seawater.

For this kind of applications, duplex grades are commonly used and to find operational limitation for different grades in this kind of service, advanced tests in model heat exchangers using chlorinated, natural seawater were performed [2]. The results show that the inside skin temperature limit for super duplex UNS $\mathrm{S} 32750$ is $65^{\circ} \mathrm{C}$ while for a hyper duplex UNS S32707 the temperature limit is $95^{\circ} \mathrm{C}$ (Table 2). This means for applications where the end-user before was limited to titanium or copper alloys, the hyperduplex grades UNS S32707 is now a viable alternative. The results also clearly show that duplex UNS S32205 is unsuitable for use in chlorinated seawater.

Table 2. Results from testing in [2], showing the limitations of inside tube wall skin temperature for three duplex grades in chlorinated, natural seawater.

\begin{tabular}{|c|c|c|c|c|c|c|}
\hline \multirow{2}{*}{ Material } & \multicolumn{5}{|c|}{ Seawater temperature $35^{\circ} \mathrm{C}$} & $\begin{array}{l}\text { Seawater } \\
\text { temp. } 20^{\circ} \mathrm{C}\end{array}$ \\
\cline { 3 - 7 } \multicolumn{2}{|c|}{} & \multicolumn{5}{|c|}{ Tube outside / inside skin temperature } \\
\hline Tube & PREN & $65^{\circ} \mathrm{C} / 50^{\circ} \mathrm{C}$ & $105^{\circ} \mathrm{C} / 70^{\circ} \mathrm{C}$ & $135^{\circ} \mathrm{C} / 85^{\circ} \mathrm{C}$ & $155^{\circ} \mathrm{C} / 95^{\circ} \mathrm{C}$ & $170^{\circ} \mathrm{C} / 95^{\circ} \mathrm{C}$ \\
\hline S32205 & 36 & Pitting & Pitting & - & - & - \\
\hline S32750 & 43 & No pitting & Pitting & - & - & - \\
\hline S32707 & 49 & No pitting & No pitting & No pitting & No pitting & No pitting \\
\hline
\end{tabular}

\subsubsection{Hydrochloric acid corrosion and salt} deposits 
There are always some small amount of chlorides and other salts present in the refinery distillation processes. These chlorides will to some extent be in the form of hydrochloric acid which will condense on the cold tubes in the overhead condenser. Hydrochloric acid is a strong acid which is highly corrosive to stainless steel (Fig. 3) and nickel base alloys and will give rise to general corrosion. To mitigate this corrosion, water wash and neutralizing amines or ammonia is commonly used. Some of the salts formed when hydrochloric acid is neutralized using a base have low solubility in hydrocarbons and since the amount of water is limited, the salt commonly deposits on the tubes or accumulates in the bottom of the heat exchanger. The salts deposits then act as a crevice and can lead to severe under deposit corrosion. Most commonly, such under deposit corrosion is caused by ammonium chloride.

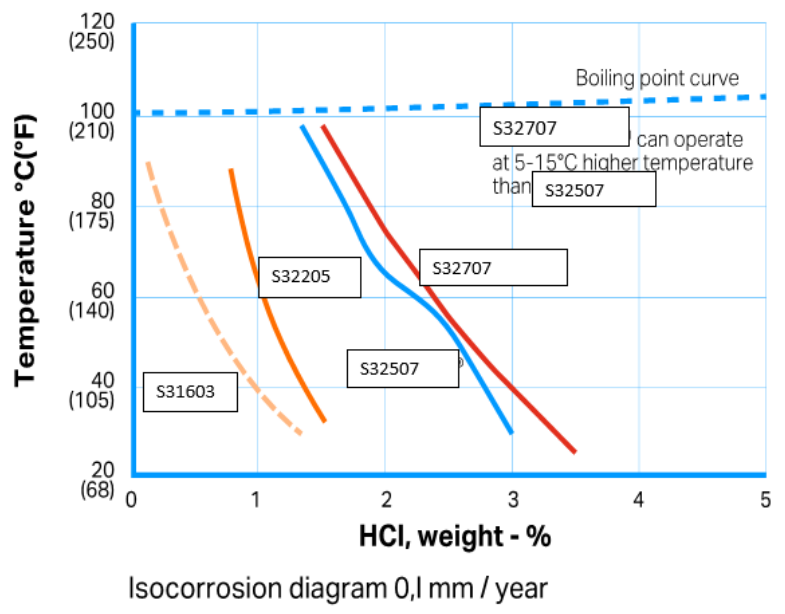

Fig. 3 Hydrochloric acid corrosion resistance of different stainless steels

\subsubsection{Chloride induced stress corrosion cracking (CI-SCC)}

Stainless steel alloys that contain an austenitic phase are all susceptable to Cl-SCC. The most susceptable alloys to $\mathrm{Cl}-\mathrm{SCC}$ are the 300 -series austenitic grades. For S30403 or S31603, Cl-SCC can develop already at such low chloride concentrations as $10 \mathrm{ppm}$ and temperatures as low as $60^{\circ} \mathrm{C}$ (Fig. 4). The resistance towards this failure mechanism increases with increased alloying content, and high alloyed stainless steel such as $6 \mathrm{Mo}$ grades are in principal immune to $\mathrm{Cl}-\mathrm{SCC}$ under wet corrosive conditions. Since a ferritic phase is immune to Cl-SSC, duplex stainless steel grades with their dual microstructure exhibits a natural high resistance towards this corrosion mechanism. This natural resistance of duplex stainless steel grades also means that they do not need to be stress relived after being cold worked, for example cold bending of tubes.

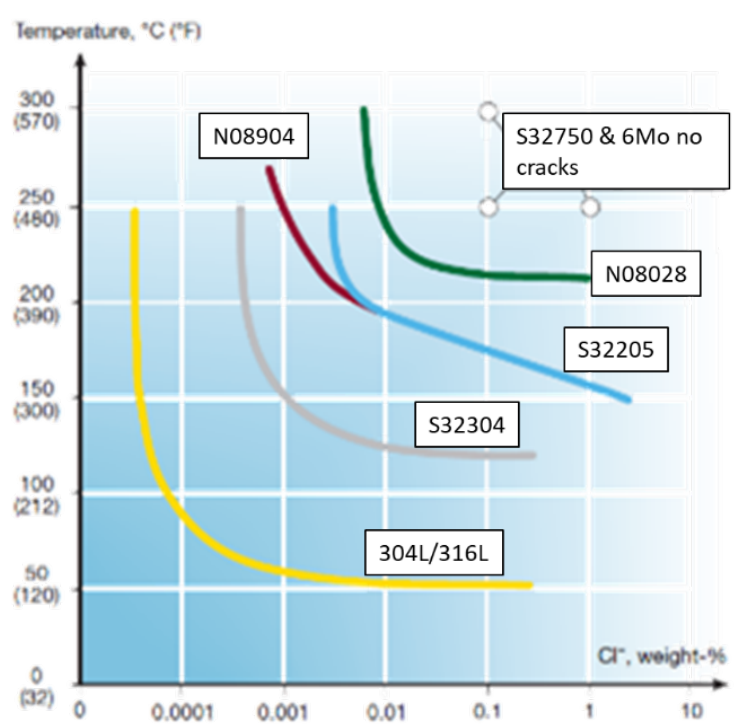

Fig. 4 Stress corrosion cracking (SCC) resistance for some stainless steel grades in oxygen-bearing neutral chloride solutions. The line for S30403 or S31603 (304L/316L) steels is a compilation of practical experience and laboratory results.

\section{Refinery Applications}

\subsection{Overhead condensers}

The main issues facing overhead condensers are caused by carry over of chloride species with the light-end hydrocarbons and water. The chlorides can lead to several corrosion issues such as pitting corrosion, crevice corrosion, Cl-SCC and general corrosion due to hydrochloric acid dew point. If the hydrochloric acid is neutralized using ammonia, formation of solid ammonium chloride can give rise to under deposit corrosion.

\subsubsection{Case study 1}

Duplex UNS S32205 tubes installed in a crude unit overhead condenser failed after 18 months in service due to the formation of ammonium chloride and following under deposit corrosion [3]. On the shell side of the heat exchanger the process media was the distillation top fraction containing naphtha and water, $\mathrm{T}_{\text {in }}=130^{\circ} \mathrm{C}, \mathrm{T}_{\text {out }}$ $=78^{\circ} \mathrm{C}$, and on the tube side diluted crude was preheated, $\mathrm{T}_{\text {in }}=44^{\circ} \mathrm{C}, \mathrm{T}_{\text {out }}=77^{\circ} \mathrm{C}$. The tube bundle was replaced with hyper duplex tubes $\mathrm{S} 32707$ which after 7 years of operation were still in good condition.

\subsubsection{Case study 2}

An overhead condenser was cooled using chlorinated seawater. On the shell side of the heat exchanger was the distillation top fraction with an inlet temperature of 150$155^{\circ} \mathrm{C}$ while the tube side contained the chlorinated seawater. The calculated tube skin temperature towards the seawater was $77^{\circ} \mathrm{C}$. The first installed tube material was aluminium brass C68700 which failed due to high flow rate and following erosion corrosion on the tube 
side. As the skin temperature of the tube towards the seawater was so high, super duplex could not be used and the material choice therefore fell on the hyper duplex grade S32707. The tubes were installed in 2010 and have been in service since then without any corrosion issues.

\subsection{Hydrodesulphurisation (HDS) unit}

Heat exchangers in hydrodesulphurisation units can experience several different corrosion issues. The most common corrosion mechanisms in the HDS unit are ClSCC, pitting corrosion, under deposit corrosion from primarily ammonium salts species, erosion corrosion from solid salts and possibly naphthenic acid corrosion. Especially the last heat exchanger in the reactor effluent exchanger train, the reactor effluent air cooler (REAC), will show very short life time if made of carbon steel. In the REAC the material choice is usually governed by the standard API 932-B [4] and N08825 is a standard grade.

In the past, duplex S32205 has been used extensively in REAC's. Although this material has worked well in the vast majority of the cases, there has also been several severe failures. The failures have been attributed to high ferrite content in the heat affected zone (HAZ) of welds which has led to hydrogen embrittlement of the material with following cracking. For this reason, the trend within the refinery industry is to step away from this solution and use austenitic grades instead.

\subsubsection{Case study 1}

A REAC used carbon steel tubes which needed to be replaced every 18 months due to erosion corrosion from solid salts. The operating conditions for the unit were $T_{\text {in }}$ $=160^{\circ} \mathrm{C}$ and $\mathrm{T}_{\text {out }}=40^{\circ} \mathrm{C}$ and the process media was kerosene containing $1 \% \mathrm{H}_{2} \mathrm{~S}$. Duplex S32205 tubes with aluminium finning was installed in REAC units as replacement material and after over 4 years of operation the unit was still in excellent condition.

\subsubsection{Case study 2}

In a second case, carbon steel was replaced in 8 REAC units. The operation conditions were $\mathrm{T}_{\text {in }}=136^{\circ} \mathrm{C}$ and $\mathrm{T}_{\text {out }}=45^{\circ} \mathrm{C}$ with a process stream contain $1 \% \mathrm{H}_{2} \mathrm{~S}$, hydrocarbons and small amounts of chlorides. The replacement material was N08825 which has provided good service since 2013.

\subsection{Delayed coker units}

Delayed coker units are used to process heavy residues from for example vacuum distillation units (VDU) and fluid catalytic crackers (FCC). The heavy residues are in the delayed coker converted to lighter hydrocarbons, gas oil and petroleum coke. Since sulphur species tend to accumulate in heavy petroleum fractions the delayed coker unit is classified as a high sulphide containing unit.
The process media is usually also high in naphthenic acid.

\subsubsection{Case study}

10 heat exchangers were to be installed for cooling coker products. On the shell side was coker fraction overheads with high $\mathrm{H}_{2} \mathrm{~S}$ content and $\mathrm{T}_{\text {in }}=56-88^{\circ} \mathrm{C}$ and $\mathrm{T}_{\text {out }}=$ $40^{\circ} \mathrm{C}$. On the tube side was cooling water containing $600-900 \mathrm{ppm}$ chlorides and $\mathrm{T}_{\text {in }}=33^{\circ} \mathrm{C}$ and $\mathrm{T}_{\text {out }}=45^{\circ} \mathrm{C}$. In most cases this would have been a good application for a duplex grade, but due to the high $\mathrm{H}_{2} \mathrm{~S}$ content an austenitic grade was preferred. At first, N08825 was considered for the project but since this grade has rather poor pitting corrosion resistance $(\mathrm{PRE}=29)$, corrosion from the cooling water was a concern. It was therefore decided to use N08028 (PRE = 38) instead. Apart from N08028 being a superior alloy compared to N08825 for this application, the lower nickel content also meant that the material cost for the tube bundles was significantly lower. The heat exchangers have now been in service for almost 10 years and are still in perfect condition

\section{Conclusion}

Choosing a duplex stainless steel in refineries is usually an interesting solution for applications where austenitic or nickel base alloys are not mandatory to use. Apart from good corrosion resistances, duplex grades high mechanical strength can also be utilised to gain a better engineered solution compared to austenitic alternatives. Regarding nickel base alloys there is usually an over confidence in their suitability for an application. In most cases they will work just fine, but at a very high cost, and in other cases they will fail prematurely. There are however several advanced and much smarter alloyed stainless steel solutions, both duplex and austenitic, that will give much more value for the money spent. Spending some time evaluating the alternatives to nickel base alloys can therefore be time well invested.

\section{References}

1. ASTM Standard G48-11, 2015, "Standard Test Methods for Pitting and Crevice Corrosion Resistance of Stainless Steels and Related Alloys by Use of Ferric Chloride Solution", ASTM International, West Conshohocken, PA, USA, 2015.

2. J. Eidhagen, et. Al. paper 9421 (NACE Corrosion 2010)

3. M. Senatore, J. Höwing, paper 10357 (NACE Corrosion 2010)

4. API RP 932-B, 'Design Materials, Fabrication, Operation and Inspection Guidelines for Corrosion Control in Hydroprocessing Reactor Effluent Air Cooler (REAC) Systems", American Petroleum Institute (API), USA, 2nd Edition, March 2012 